\title{
Improvement of Electrical Properties of p-type GaN and Au Contact Interface*
}

\author{
by Aiman bin Mohd Hali1**, Keisuke Tsuchida**, Masakatsu Maeda*** and Yasuo Takahashi****
}

\begin{abstract}
In order to improve electrical conductivity of Mg-doped p-GaN, the enhancement of $\mathrm{H}$ release from $\mathrm{Mg}$-doped $\mathrm{p}$-GaN were attempted by applying current flow and electrical field through the $\mathrm{p}-\mathrm{GaN}$ substrates during low temperature annealing. The microstructure and electrical properties after annealing were then investigated by transmission electron microscopy observation, direct current conduction test and Hall effect measurement. The results reveal that no reaction occurs between deposited Au film and GaN substrate during annealing at $573 \mathrm{~K}$ for $3600 \mathrm{~s}$. The electrical conductivity does not show any improvement only by applying electrical field or by annealing at $573 \mathrm{~K}$ for $3600 \mathrm{~s}$ without current flow. It is likely due to the limited mobility of $\mathrm{H}$ within $\mathrm{p}-\mathrm{GaN}$. However, by applying current flow under the constant voltage of $30 \mathrm{~V}$ during annealing at $573 \mathrm{~K}$ for $3600 \mathrm{~s}$, a significant improvement of the electrical conductivity has been observed. By applying electrical field and current flow during annealing at $573 \mathrm{~K}$ for $3600 \mathrm{~s}$, the $\mathrm{H}$ release from p-GaN was enhanced and $\mathrm{Mg}$ was activated, resulting in increasing carrier concentration of acceptor and improving the electrical conductivity.
\end{abstract}

Key Words: p-type Gallium Nitride, Au Film, Hydrogen Release, Annealing, Current Flow, Electrical Field, Microstructures, Electrical Properties

\section{Introduction}

Silicon ( $\mathrm{Si}$ ) is still now used mainly as power electronic devices. But, it is important to seek for better alternative materials for use in the next-generation power electronic devices due to the physical limitation of silicon. Gallium nitride $(\mathrm{GaN})$ is one of the most promising candidates. Also, GaN has an advantage as a high frequency communication element. GaN-based power electronic devices promise higher energy efficiency devices, with capability of handling higher power and longer service life ${ }^{1,2)}$, compared with silicon devices. However, in spite of having a significant development in the crystal growth ${ }^{3,4)}$ and devise processing technology of light emitting diodes (LED) and laser diodes $(\mathrm{LDs})^{5}$, the application of $\mathrm{GaN}$ semiconductor to power electronic devices is still far from real.

One of the main problems in realizing GaN-based power electronic devices is related to the fact that the only effective p-type dopant known for $\mathrm{GaN}$ is magnesium $(\mathrm{Mg})$. Although some decent annealing methods were developed ${ }^{6,7)}$ after the breakthrough discovery of Mg-activation by electron-beam irradiation $^{8)}$, new developments of improvement methods for

${ }^{*}$ Received: 2014.12 .28

${ }^{* *}$ Student Member, Division of Materials and Manufacturing Science, Graduate School of Engineering, Osaka University, 2-1 Yamadaoka, Suita, Osaka, 565-0871 Japan

*** Member, College of Industrial Technology, Department of Mechanical Engineering, Nihon University, 2-1 Izumi-cho 1-chome, Narashino, Chiba, 275-8575 Japan

${ }^{* * * *}$ Member, Joining and Welding Research Institute, Osaka University, 11-1 Mihogaoka, Suita, Osaka 565-0047, Japan p-type GaN conductivity has not been accomplished. It is reported that only approximately one percent of doped magnesium atoms are activated during $\mathrm{Mg}$-activation ${ }^{9,10)}$. This is due to the presence of hydrogen $(\mathrm{H})$ within the $\mathrm{Mg}$-doped $\mathrm{GaN}$, incorporated during growth ${ }^{11)}$. $\mathrm{H}$ is known to electrically passivate the acceptors ${ }^{12}$. This passivation is attributed to the formations of neutral $\mathrm{Mg}-\mathrm{H}$ complexes where $\mathrm{H}$ is bonded interstitially to a neighboring nitrogen atom ${ }^{13-15)}$. Furthermore, in order to more improve p-type conductivity, postgrowth activation of $\mathrm{Mg}$ by thermal annealing, which releases $\mathrm{H}$ from $\mathrm{GaN}$, is necessary ${ }^{6}$. The thermal annealing is believed to releases $\mathrm{H}$ from GaN but not so effective. The high annealing temperature (973 K) 6), required to activate p-type conductivity, damages GaN device because $\mathrm{GaN}$ is decomposed and $\mathrm{N}$ vacancy concentration increases in $\mathrm{GaN}$, i.e., $\mathrm{p}-\mathrm{GaN}$ properties can be failed. Thus, it is important to understand and improve the processes of $\mathrm{H}$ release from GaN.

In the present study, in order to improve the conductivity of $\mathrm{Mg}$-doped $\mathrm{p}-\mathrm{GaN}$, the enhancement of $\mathrm{H}$ release from $\mathrm{Mg}$-doped p-GaN under temperatures much lower than $973 \mathrm{~K}$ is attempted by applying electrical field and current flow through the $\mathrm{p}-\mathrm{GaN}$ substrates during low temperature annealing $(573 \mathrm{~K})$. In that stage, pure $\mathrm{Au}$ is used as an electric pad (contact) film because $\mathrm{Au}$ does not react with nitrogen in $\mathrm{GaN}$ and has a work function of $5.1 \mathrm{eV}$. The microstructure and electrical properties after annealing used in the present study were then analyzed by transmission electron microscopy (TEM), direct current (DC) conduction tests and Hall effect measurement. 


\section{Experimental procedure}

Substrates used in the present study were 2.0- $\mu$ m-thick p-type $\mathrm{GaN}$ epitaxially grown on a $330-\mu \mathrm{m}$-thick sapphire (0001) wafer with undoped $\mathrm{GaN}$ buffer layer. The thickness of undoped GaN was $2.3 \mu \mathrm{m}$. The surface orientation and carrier concentration of the substrate were (0001) Ga-face and $3 \times 10^{17} \mathrm{~cm}^{-3}$, respectively. The sizes of all substrates were $4.0-\mathrm{mm}$-square. The electric pad (contact) areas were obtained by using 1.0-mm-wide Al masking ribbons. Before the sputter depositing process, the substrates were cleaned with acetone applying ultrasonic vibration. After that, the substrates were fixed on the depositing plate designed in a radio-frequency magnetron sputtering deposition apparatus. High-purity Au (99.95 mass \%) plates was used as a target material, i.e., $\mathrm{Au}$ atoms was sputter-deposited as a contact thin film on $\mathrm{p}-\mathrm{GaN}$.

Before sputter depositing Au thin film on the electric pad area, the surfaces of $\mathrm{Au}$ target and substrates ( $\mathrm{p}-\mathrm{GaN}$ with pad areas) were sputter-cleaned to remove native oxide layer. The sputter cleaning of $\mathrm{Au}$ target and substrates were carried out under $0.8 \mathrm{~Pa}$ of high-purity Ar (99.9999 volume \%) under a radio-frequency power of $100 \mathrm{~W}$ and $200 \mathrm{~W}$, respectively. The sputter cleaning time was $300 \mathrm{~s}$. The sputter deposition of $\mathrm{Au}$ thin film was performed under 0.8 Pa high-purity $\operatorname{Ar}(99.9999$ volume \%) under a radio-frequency power of $100 \mathrm{~W}$ for $36 \mathrm{~s}$.

Some of the deposited samples were then subjected to annealing at $573 \mathrm{~K}$ under $0.1 \mathrm{MPa}$ of nitrogen ambient for $3600 \mathrm{~s}$. In the present study, two methods of applying voltage through the sample during annealing were used. These methods are to be referred to as Method (a) for applying electrical field under the condition of DC $100 \mathrm{~V}$ without current flow and Method (b) for applying current flow under the condition of DC $30 \mathrm{~V}$. The schematic illustrations of these methods are shown in Figure 1. The annealing conditions of the samples are shown in Table 1.

The microstructure and electrical properties of the samples were then analyzed by TEM observation and conduction tests at room temperature and Hall effect measurement using the van der Pauw method at room temperature.

\section{Results and discussion}

Figure 2 shows the TEM microstructure of the $\mathrm{p}-\mathrm{GaN} / \mathrm{Au}$ contact interface (sample 3) after annealing at $573 \mathrm{~K}$ for $3600 \mathrm{~s}$. As seen in the bright-field image shown in Figure 2 (a), a layer of $\mathrm{Au}$ film with approximately 400-nm-thickness is observed adjacent to $\mathrm{GaN}$ substrate. The electron diffraction pattern of the whole area shown in Figure 2 (a) was taken. The result is shown in Figure 2 (b). The diffraction pattern consists of only net pattern

\begin{tabular}{|c|c|c|}
\hline Sample No. & $\begin{array}{c}\text { Annealing } \\
\text { Temperatures }\end{array}$ & $\begin{array}{c}\text { Methods of } \\
\text { Applying Voltages }\end{array}$ \\
\hline 1 (as-deposited) & - & - \\
\hline 2 & - & (a) \\
\hline 3 & $573 \mathrm{~K}$ & - \\
\hline 4 & $573 \mathrm{~K}$ & (a) \\
\hline 5 & $573 \mathrm{~K}$ & (b) \\
\hline
\end{tabular}

Table 1 The annealing conditions of the samples.

(a)
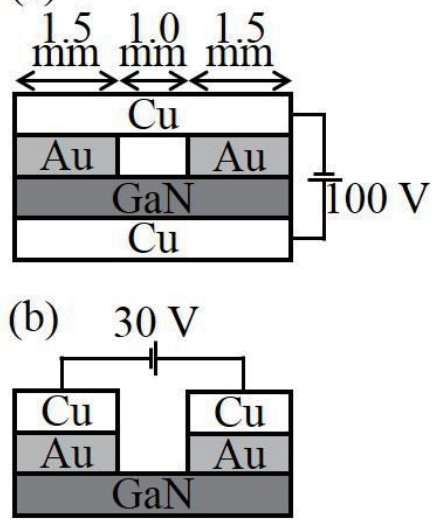

Figure 1 Schematic illustrations of the methods of applying voltages during annealing at $573 \mathrm{~K}$ : (a) applying electrical field under the condition of DC $100 \mathrm{~V}$ without current flow, (b) applying current flow under the condition of DC $30 \mathrm{~V}$.
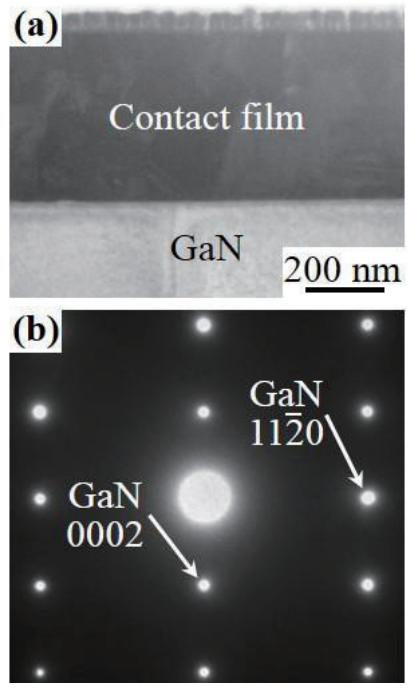

Figure 2 Microstructure of the $\mathrm{p}-\mathrm{GaN} / \mathrm{Au}$ contact (sample 3) after annealing. (a) bright-field image, (b) selected area electron diffraction pattern of the area shown in (a).

of GaN. This result indicates that after the annealing at $573 \mathrm{~K}$ for $3600 \mathrm{~s}$, the crystallization of $\mathrm{Au}$ film still does not occur or the $\mathrm{Au}$ film is in a very early stage of crystallization. Thus, no diffraction pattern consisting of Au net pattern is observed.

The fact that any net pattern except for GaN is not observed indicates that no reactions occur between deposited $\mathrm{Au}$ film and $\mathrm{GaN}$ substrate during the annealing at $573 \mathrm{~K}$. If the reaction occurs at the interface between $\mathrm{GaN}$ and $\mathrm{Au}$ film, Au-Ga intermetallic compounds will be produced at the interface. 
Compared with $\mathrm{Au}$, these intermetallic compounds have lower values of work functions. Thus, the formation of these compounds at the interface will increase the Schottky barrier height and deteriorate the electrical properties of the contact. This reaction will also introduce unstable $\mathrm{N}$ atoms within $\mathrm{p}-\mathrm{GaN}$ substrates, which consequently diffuse to the interface of $\mathrm{p}-\mathrm{GaN}$ and $\mathrm{Au}$ film and form voids. The formation of voids at the interface decreases the area of contact interface and deteriorates the electrical properties of the $\mathrm{p}-\mathrm{GaN} / \mathrm{Au}$ contact. As seen in Figure 2 (a), no reaction layers exist at the interface. So, the reaction of $\mathrm{Au}-\mathrm{Ga}$ under the annealing condition of $573 \mathrm{~K}$ for $3600 \mathrm{~s}$ can be negligible, i.e., the deterioration of electrical properties of the contact have been avoided by annealing at low temperature.

Figure 3 shows the electrical conduction profile ( $I-V$ curves) of the samples, where $I$ is the current and $V$ is the voltage between electric pads. Numbers inset in Figure 3 correspond to sample numbers shown in Table 1. The electrical conduction profiles of sample 2 and sample 3 shows no clear differences from that of sample 1. As seen in Figure 3, marks of $\diamond, \square$, and $\triangle$ are overlapped. That is, no improvement of conductivity has been achieved. This implies that $\mathrm{H}$ release from $\mathrm{p}-\mathrm{GaN}$ cannot be enhanced by only applying electrical field or annealing at $573 \mathrm{~K}$. $\mathrm{H}$ within $\mathrm{p}-\mathrm{GaN}$ has a very limited mobility at low temperatures because $\mathrm{H}$ combines with $\mathrm{Mg}$. Thus, only the electric field applying or low temperature annealing of $573 \mathrm{~K}$ is not effective to release $\mathrm{H}$ from $\mathrm{p}-\mathrm{GaN}$.

However, by applying electrical field during the annealing at $573 \mathrm{~K}$ (sample 4; marks of $\boldsymbol{\Delta}$ ), some improvement of electrical conductivity has been achieved, as can be seen in Figure 3. This result reveals that a significant amount of $\mathrm{H}$ within $\mathrm{p}-\mathrm{GaN}$ has been released by applying the electrical field at $573 \mathrm{~K}$, resulting in improving $I-V$ properties. It is likely that during annealing at $573 \mathrm{~K}, \mathrm{H}$ within $\mathrm{p}-\mathrm{GaN}$ formed $\mathrm{H}$ ions and $\mathrm{H}$ ions have enough mobility to be effected by the applied electrical field. $\mathrm{H}$ ions are moved near the interface between contact film and $\mathrm{p}-\mathrm{GaN}$ by the applied electrical field, thus increasing the concentration of $\mathrm{H}$ at the interface. $\mathrm{H}$ diffuses along the interface to the surface of $\mathrm{GaN}$ and can be released to the outside. The higher concentration of $\mathrm{H}$ at the interface enhances the $\mathrm{H}$ release from the surface of $\mathrm{p}-\mathrm{GaN}$. The $I-V$ properties improvement of sample 4 shown in Figure 3 indicate the increase of carrier (accepter) concentration and decrease of Schottky barrier width at the contact interface have been achieved. These improvements can be attributed to the enhancement of $\mathrm{H}$ release from $\mathrm{p}-\mathrm{GaN}$.

As can be seen in Figure 3 (sample 5; marks of $\mathbf{0}$ ), further improvement is observed by applying current flow under the condition of DC $30 \mathrm{~V}$ during the annealing at $573 \mathrm{~K}$. This

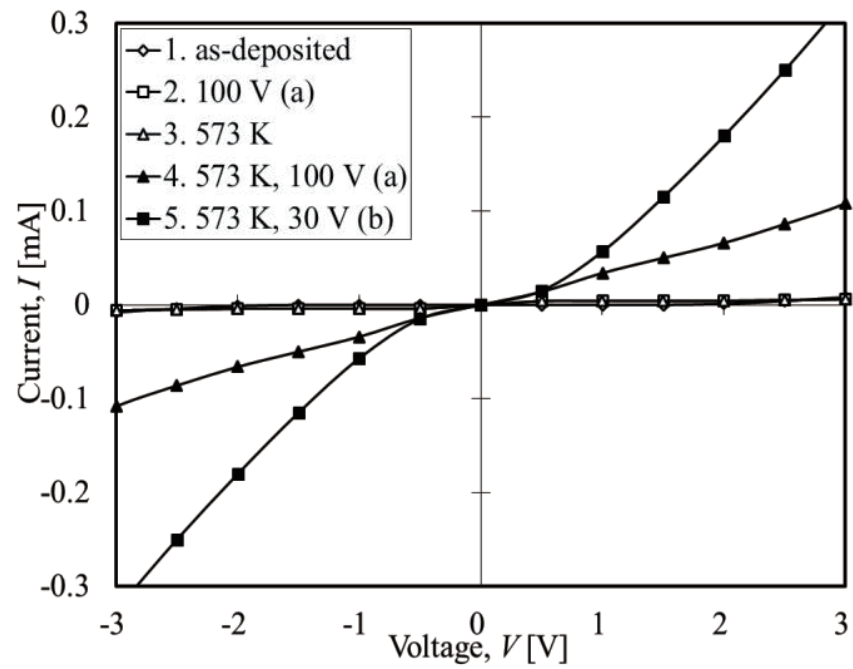

Figure 3 Electrical conduction profiles of the samples.

suggests that the amount of $\mathrm{H}$ released from $\mathrm{p}-\mathrm{GaN}$ of sample 5 are much higher compared to other samples $2 \sim 4$. If using Method (b), the interface and surface area necessary for releasing $\mathrm{H}$ from $\mathrm{GaN}$ is much smaller, compared with using the Method (a). In Method (a), the effective surface for releasing $\mathrm{H}$ from $\mathrm{GaN}$ is equal to the exposed p-GaN surface. The surface of the deposited $\mathrm{Au}$ film must not be an effective surface for $\mathrm{H}$ release, because $\mathrm{Au}$ film cannot contain $\mathrm{H}$. On the other hand, in Method (b), the effective area for $\mathrm{H}$ release is only the interface (contact area) between $\mathrm{Au}$ film and $\mathrm{p}-\mathrm{GaN}$ and the surface of $\mathrm{GaN}$ adjacent to the contact area.

With a smaller effective surface and interface area for $\mathrm{H}$-release, the $\mathrm{H}$ concentration is much higher in Method (b), compared with Method (a). The increase of $\mathrm{H}$ concentration can enhance the $\mathrm{H}$ release. As a result, Method (b) gave the best I-V curve in the present study although Ohmic properties could not be obtained.

Finally, in order to investigate the dominant carrier-type of the sample, sample 3 (annealed at $573 \mathrm{~K}$ for $3600 \mathrm{~s}$ ) was subjected to the Hall effect measurement at the room temperature. The result revealed that the dominant carrier-type for the sample was p-type; the dominant carrier-type of the samples could be retained after the annealing at $573 \mathrm{~K}$ for $3600 \mathrm{~s}$. The annealing at $573 \mathrm{~K}$ for $3600 \mathrm{~s}$ is suitable for improving the electrical conductivity of $\mathrm{p}-\mathrm{GaN}$, while maintaining the p-type carrier.

In the present study, as shown in electrical conduction profiles in Figure 3, the I-V properties of the samples are not ohmic. Ohmic contact is necessary to achieve accurate measurement of carrier concentration. Therefore, the measured carrier concentration of the samples were considered not accurate and have been omitted. In the present study, the carrier concentration values obtained by Hall effect measurement were only be used qualitatively to determine the dominant carrier-type of the samples. 


\section{Conclusions}

In the present study, in order to improve the conductivity and electric contact properties of Mg-doped $\mathrm{p}-\mathrm{GaN}$, the enhancement of $\mathrm{H}$ release from $\mathrm{Mg}$-doped $\mathrm{p}-\mathrm{GaN}$ are attempted by applying current flow and electrical field through the substrates during low temperature annealing at $573 \mathrm{~K}$. The microstructure and electrical properties after annealing were then analyzed by transmission electron microscopy (TEM) observation, direct current (DC) conduction tests and Hall effect measurement. The result reveals that no reaction occur between deposited $\mathrm{Au}$ film and $\mathrm{GaN}$ substrate during annealing at $573 \mathrm{~K}$ for $3600 \mathrm{~s}$. The electrical conductivity of $\mathrm{p}-\mathrm{GaN}$ does not show any improvement only by applying electrical field or only by annealing at $573 \mathrm{~K}$ for $3600 \mathrm{~s}$. This is likely due to the limited mobility of $\mathrm{H}$ within $\mathrm{p}-\mathrm{GaN}$. However, by applying electrical field or current flow during annealing at $573 \mathrm{~K}$ for $3600 \mathrm{~s}$, significant improvement of electrical conductivity of $\mathrm{p}-\mathrm{GaN}$ has been achieved. By applying electrical field or current flow during annealing at $573 \mathrm{~K}$ for 3600 $\mathrm{s}$, the concentration of $\mathrm{H}$ near the surface and interface was increased, thus it was suggested that this high concentration of $\mathrm{H}$ enhanced the $\mathrm{H}$ release from $\mathrm{p}-\mathrm{GaN}$ and improved the electrical conductivity of $\mathrm{p}-\mathrm{GaN}$.

\section{Acknowledgements}

The authors express their gratitude to Prof. H. Yasuda and Mr. E. Taguchi for their kind permission and assistance to use facilities in the Research Center for Ultra-High Voltage Electron Microscopy, Osaka University, Japan.

\section{Reference}

1) M. Asif Khan, Q. Chen, M. S. Shur, B. T. Dermott, J. A. Higgins,J. Burm, W. J. Schaff and L. F. Eastman: GaN based heterostructure for high power devices, Sol. Stat. Electron., 41 (1997), 1555-1559.

2) A.P. Zhang, F. Ren, T. J. Anderson, C. R. Abernathy, R. K. Singh, P.
H. Holloway, S. J. Pearton, D. Palmer and G. E. McGuire: High-Power GaN Electronic Devices, Critic. Rev. Solid. Stat. Mater. Sci., 27 (2002), 1-71.

3) K. Motoki, T. Okahisa, S Nakahata, N. Matsumoto, H. Kimura, H. Kasai, K. Takemoto, K. Uematsu, M. Ueno, Y. Kumagai, A. Koukitu and H Seki: Growth and characterization of freestanding GaN substrates, J. Cryst. Growth, 237-239 (2002), 912-921.

4) Y. Mori, M. Imade, K. Murakami, H. Takazawa, H. Imabayashi, Y. Todoroki, K. Kitamoto, M. Maruyama, M. Yoshimura, Y. Kitaoka and T. Sasaki: Growth of bulk GaN crystal by Na flux method under various conditions, J. Cryst. Growth, 350 (2012), 72-74.

5) I. Akasaki: Key inventions in the history of nitride-based blue LED and LD, J. Cryst. Growth, 300 (2007), 2-10.

6) S. Nakamura, T. Mukai, M. Senoh and N. Iwasa: Thermal Annealing Effects on P-Type Mg-Doped GaN Film, Jpn. J. Appl. Phys., 31 (1992), L139-L142.

7) S. Nakamura, M. Senoh and T. Mukai: Highly P-Typed Mg-Doped GaN Films Grown with GaN Buffer Layers, Jpn. J. Appl. Phys., 30 (1991), L1708-L1711

8) H. Amano, M. Kito, K. Hiramatsu and I. Akasaki: P-Type Conduction in Mg-Doped GaN Treated with Low-Energy Electron Beam Irradiation (LEEBI), Jpn. J. Appl. Phys., 28 (1989), L2112-L2114

9) R. Piotrzkowski, E. Litwin-Staszewska, T. Suski and I. Grzegory: Study of dopant activation in bulk GaN: Mg, Physica B, 308-310 (2001), 47-50.

10) E. Litwin-Staszewska, T. Suski, R. Piotrzkowski, I. Grzegory, M. Bockowski, J. L. Robert, L. Konczewicz, D. Wasik, E. Kaminska, D. Cote and B. Clerjaud: Temperature dependence of electrical properties of gallium-nitride bulk single crystals doped with $\mathrm{Mg}$ and their evolution with annealing, J. Appl. Phys., 89 (2001), 7960-7965.

11) S. J. Pearton, J. C. Zolper, R. J. Shul, and F. Ren: GaN: Processing, defects, and devices, J. Appl. Phys., 86 (1999), 1-78.

12) S. Nakamura, N. Iwasa, M. Senoh, and T. Mukai: Hole Compensation Mechanism of P-Type GaN Films, Jpn. J. Appl. Phys., 31 (1992), 1258-1266.

13) J. Neugebauer and C. G. Van De Walle: Hydrogen in GaN: Novel Aspects of a Common Impurity, Phys. Rev. Lett., 75 (1995), $4452-4455$.

14) B. Clerjaud, D. Cote, A. Lebkiri, C. Naud, J. M. Baranowski, K Pakula, D. Wasik, and T. Suski: Infrared spectroscopy of Mg-H local vibrational mode in GaN with polarized light, Phys. Rev. B, 61 (2000), 8238-8241

15) S. M. Myers, C. H. Seager, A. F. Wright, B. L. Vaandrager, and J. S Nelson: Electron-beam dissociation of the $\mathrm{MgH}$ complex in p-type GaN, J. Appl. Phys., 92 (2002), 6630-6635. 